\title{
Factors Causing Hypothermia and Rewarming Manoeuver Among Critically Ill Patients in Intensive Care Units
}

\author{
Noura Moustafa Mahmoud ${ }^{1}$ Mona Aly Mahmmed ${ }^{2}$ \& Amal Ismael Abd El-Hafez ${ }^{3}$. \\ 1. Clinical Nurse Specialist, El- Azhar University Hospital, Egypt. \\ 2. Assist Prof of Critical Nursing Care, Faculty of Nursing, Assiut University, Egypt. \\ 3. Lecturer of Critical Nursing Care, Faculty of Nursing, Assiut University, Egypt.
}

\begin{abstract}
Background: Hypothermia is a medical emergency that occurs when the patient loses heat faster than it can be produced. Aim: Identify factors that causing hypothermia and rewarming manoeuver among critically ill patients in Intensive Care Units. Design: A descriptive exploratory research design. Setting: The study was conducted at the intensive care units namely general ICU, trauma ICU, recovery area of surgical and recovery area of orthopedic at Assuit Main University hospital and general ICU and coronary care unit at El-Azhar University hospital. Patients and Method: The study sample consisted of hypothermic patients $(=100)$ and non hypothermic patients $(\mathrm{n}=130)$ were included in the study for consecutive six months. Tools were utilized for data collection tool I: patient assessment sheet, tool II hypothermia assessment sheet. Results: study Findings revealed that $99 \%$ of hypothermic patients had mild degree of hypothermia and had stage one of hypothermia. Regarding to rewarming manoeuver, it was noticed that $99 \%$ of hypothermic patients used rewarming blanket and this were effective in $(76.8 \%)$ of patients. Conclusion: This study showed that risk factors for hypothermia were diabetes mellitus (hypoglycaemia), underweight and low glasgow coma scale.
\end{abstract}

\section{Key words: Critically Ill Patients, Hypothermia \& Rewarming Manoeuver.}

\section{Introduction}

Hypothermia is common among patients who agonizes from critical illness and is associated with adverse mortality outcome whereas the presence of hypothermia may be marker of severity of illness associated with mortality and it may also result in complications that increase risk for consequent adverse outcome (Laupland et al., 2012)

The human body functions optimally with a core temperature between $36.4^{\circ} \mathrm{c}$ and $37.5^{\circ} \mathrm{c}$ and core temperature external that narrow range are poorly tolerated.

Hypothermia is defined by a core body temperature lower than $35^{\circ} \mathrm{C}\left(95^{\circ} \mathrm{F}\right)$. Below this temperature, the body loses more heat than it generates (Peiris , 2018) Actually dangerous drop in body temperature usually is caused by number of factors such as exposure to cold weather, the young and elderly, people with alcohol or drug problems, severe trauma, people with mental illness, some medications and some medical disease or conditions may decrease the body ability to adjust its internal temperature and these factors increase risk of hypothermia that depends on person`s age , body mass, body fat, overall health and length of time exposed to cold temperature (Davis, 2016) Classification of hypothermia is accidental or intentional, primary or secondary and by the degree of hypothermia.

According to degree of hypothermia can be grouped into mild - moderate and severe. mild hypothermia is core body temperature $32^{\circ} \mathrm{c}$ to $35^{\circ} \mathrm{c}$ (9o f to $95 \mathrm{f}$ ) Moderate hypothermia is core body temperature $28^{\circ} \mathrm{C}$ to $32^{\circ} \mathrm{c}(82 \mathrm{f}$ to90f) Severe hypothermia is core body temperature $<28^{\circ}$ c. (Adam\& Osborne, 2012).

Management of hypothermia depends on the degree of it. mild to moderate hypothermia is treated easily with helpful care in most clinical setting and has good patient outcome .Management of severe hypothermia is more complex and the outcome depends heavily on clinical resource .

Treatment of hypothermia is ranged from the using of passive or active rewarming techniques. The decision to use passive or active rewarming techniques should base on several clinical considerations and degree of hypothermia ( Mccullough \& Arora 2004).

When treatment was escorted by rapid rewarming, hypothermic patients had deteriorated short-term neurological outcomes and higher mortality rates. (Thompson et al., 2013).

\section{Significance of the Study}

The risk of morbidity and mortality depends on the severity of the degree of hypothermia and the underlying cause .Recovery usually complete for previously healthy individuals with mild or moderate hypothermia (mortality rate $<5 \%$ ). The mortality rates for patients with severe hypothermia especially with preexisting illness may be higher than 50\% (James, 2016)

This study will be the first study in Assuit University Hospital which will help to identify risk factor for 
hypothermia. It will be provide database that can be utilized by health team members.

\section{Aim of the study \\ The present study aims to \\ Identify factors that causing hypothermia and rewarming manoeuver among critically ill patients in Intensive Care Units. \\ Research Questions \\ To fulfill the aim of the present study, the following research questions are formulated: \\ Q1: What are the factors inducing hypothermia among critically ill patients in Intensive Care Units? \\ Q2: What is the rewarming manoeuver used for management the hypothermia among critically ill patients in Intensive Care Units?}

\section{Patients \& Method}

Study design

The present study was carried out using descriptive research design.

\section{Study setting}

The present study was conducted in the intensive care units (ICUs) namely general ICU, traumatic ICU , recovery of surgical and recovery of orthopedic at Assuit Main University hospital and general ICU and coronary care unit at El-Azhar University hospital.

\section{Sample}

Purposive sample was taken from all adult critically ill patients, their age ranged from $20-60$ years old Mean \pm SD of hypothermic patient $(37.65 \pm 11.80)$ and non hypothermic patient (42.09 \pm 17.32) admitted to the previously mentioned setting were included in the study for consecutive six months from march to end of november 2017. T Mean \pm SD his sample consisted of group 1 (hypothermic patients $n=100$ ) and group 2 (non hypothermic patients $n=130$ )

\section{Inclusion Criteria}

Male and female patients who are identified as suffering from mild hypothermia (body temperature $32^{\circ} \mathrm{c}$ to $35^{\circ} \mathrm{c}$ ) or moderate hypothermia (core body temperature $28{ }^{\circ} \mathrm{c}$ to $32^{\circ} \mathrm{c}$ ) or severe hypothermia (core body temperature $<28^{\circ} \mathrm{c}$ )

\section{Exclusion Criteria}

Any patient with the following conditions were excluded from the study such as patients with brain stem death, patient with spinal cord injury, patients with cardiac arrest before ICU admission or cardiac surgery, patients who are treated with artificial cooling (therapeutic hypothermia) and post cardiac arrest patients.

\section{Data collection tools}

Two tools were used to collect the data in this study and developed by the researcher based on the related literatures. (Seman et al., 2010, Vassal et al., 2008

\& Perlman et al., 2016)

Tool one:-Patient assessment sheet

- It comprised of four main parts.

Part I: patient characteristics and clinical data:

This part includes demographic data (patient's code , age and sex) patient's diagnosis, past medical history, temperature at ICU admission in the first 24 hours, body mass index, type of ICU, date of ICU admission, date of ICU discharge, need for mechanical ventilation, period of his hospital stay, died and survival of the patient.

Part II: Hemodynamic parameter and glasgow Coma Scale .

It comprises temperature, heart rate, blood pressure ,respiratory rate, CVP and glasgow coma scale.

Part III: clinical investigations:

This part includes (complete blood count, arterial blood gases, blood sugar, biochemical blood tests, amylase , kidney and liver function, electrolytes, urinalysis, prothrombin time and partial thromboplastin time )

Part IV: Medications administered checklist.

Tool Two: Hypothermia assessment questionnaire sheet

This tool was developed by researcher to assess and evaluate hypothermic patient .It consists of 3 parts.

Part I: This part covers degree, Time, duration of hypothermia and the included hypothermic body parts.

Part II : Rewarming manoeuver

This part includes warming environment, warm intravenous fluid and blood product, warming blankets, humidified gases and ventilation, warm diet and others

Part III: Patient out come

This part consists of three main categories as follows:

A-occurance of complications

Such as hypotension, shivering, hypovolaemia and hypomagnesaemia, metabolic acidosis ,hypokalemia , hypoglycaemia , hyperglycaemia ,bradycardia and other cardiac arrhythmia, pneumonia, pulmonary oedema, respiratory failure ,heart failure and death

B- patient survive or died

C- ICU stay

1- Administrative design

A written permission was obtained from authorized administration, faculty of nursing, head of anesthesia department at Assiut university hospital and head of anesthesia department at El Azhar university hospital to collect data from previously mentioned research setting after explanation the purpose and nature of the study. 


\section{2- Operational design}

1) Preparatory phase

1- This phase took about six months from June to end of November 2017 to end the proposal of the study.

\section{2) Ethical considerations}

Study proposal takes approved from Ethical Committee in the Faculty of Nursing,Written consent was obtained from patients or from the responsible person for the unconscious patients after explaining the nature and purpose of the study ,Patients and patients families were assured that the data of this research will not be reused without second permission, Confidentiality and anonymity was assured ,The study follows common ethical principles in clinical research ,There is no risk for studying subject during application of the research ,Patient has the right to refuse to participate or withdraw from the study without any rational at any time.

\section{3) Pilot study}

A pilot study was carried out to assess tool clarity, understandability, and applicability of the study tools. Moreover, to identify problems that may be encountered during the actual data collection. It applied on $10 \%$ patients from the entirely sample in a selected setting to check clarity and understanding of the study tool after the necessary modification was done. the pilot study patients were included in the study sample.

A review of current and international related to literature in a various Aspects of this study using books and magazines was done.

Tools developed by researcher after reviewing the related literature and revised by the supervisors staff.

Content validity : The developed tools ( I and II ) were tested the content validity by a jury of (7) experts (5) from specialists in the field of critical care nursing and (2) from intensive care medical, the necessary modification was done .

The study tools were tested for its reliability by using Crombach's Alpha Co- efficient test, it was efficient and test, was ( $(\boldsymbol{\alpha}=\mathbf{0 . 7 2 9})$ for patient assessment sheet (Tool I) and $(\boldsymbol{\alpha}=\mathbf{0 . 8 3 1})$ for hypothermic assessment sheet (Tool II) .

\section{4) Data collection}

The whole duration for data collection took about six months from June to November 2017. The data were collected from the first day of admission after stabilization of the patient's condition and then at at $3^{\text {rd }}$ day of patient admission and then data was recorded in the developed tools.

All patients (hypothermic and non hypothermic ) admitted in the previous mentioned ICUs were assessed regarding patient characteristics and clinical data by using tool one part I. Temperature was measured using mercury thermometer placed under the axillary. All patients (hypothermic and non hypothermic) were assess related to heart rate, respiratory rate, C.V.P and blood pressure by using tool one part II.

All patients (hypothermic and non hypothermic) were assess related Laboratory investigation such as complete blood count, electrolytes, renal function, liver function, coagulation profile and arterial blood gases were done for each patient and report their results to detect the factors associated with the occurrence of hypothermia by using tool one part III.

All patients (hypothermic and non hypothermic) were assess related Medication taken from the patient's chart to detect the drug induced hypothermia by using tool one part IV . Only hypothermic patients were assess related degree of hypothermia mild hypothermia (temperature $32^{\circ} \mathrm{c}$ to $35^{\circ} \mathrm{c}$ ) or moderate hypothermia (temperature $28^{\circ} \mathrm{c}$ to $32^{\circ} \mathrm{c}$ ) or severe hypothermia (temperature $<28^{\circ} \mathrm{c}$ ), duration, time of hypothermia and the included hypothermic body parts by using tool two part I.

\section{Evaluation phase}

Every hypothermic patients were evaluated regarding rewarming maneouver used and their effectiveness by using tool two part II. Added part III in the tool two which was needed when the collection of data from cases in the hospital and this consist of occurance of complications, patient survive or died and ICU stay to assess patient outcome. Hypothermic patients were assess related occurance of complications, patient survive or died and ICU stay by using tool two part III

\section{3-Statistical design}

Data entry and statistically analysis were done using SPSS 16.0 Statistical Soft Ware Package. Data was presented using descriptive statistics in the form of frequencies, percentages, mean, standard deviation, range, and chi-square. Pearson correlation analysis was used for assessment of the inter-relations among quantitative variables. Statistical significance was considered at $\mathrm{P}$-value $\leq 0.05$.

Limitations of the study: Some laboratory investigations are not completed because it is not routinely done and done these were coasted for the patient. 


\section{Results}

Table (1): Clinical characteristics for the hypothermic and non hypothermic patients.

\begin{tabular}{|c|c|c|c|c|c|}
\hline \multirow[t]{2}{*}{ Variables } & \multicolumn{2}{|c|}{$\begin{array}{c}\text { Hypothermia } \\
(n=100)\end{array}$} & \multicolumn{2}{|c|}{$\begin{array}{c}\text { Non-hypothermia } \\
(n=130)\end{array}$} & \multirow[t]{2}{*}{ P-value } \\
\hline & No. & $\%$ & No. & $\%$ & \\
\hline \multicolumn{5}{|l|}{ Sex: } & \multirow{3}{*}{0.162} \\
\hline Male & 66 & 66.0 & 74 & 56.9 & \\
\hline Female & 34 & 34.0 & 56 & 43.1 & \\
\hline \multicolumn{5}{|l|}{ Age: (years) } & \multirow{3}{*}{0.181} \\
\hline Mean \pm SD & \multicolumn{2}{|c|}{$37.65 \pm 11.80$} & \multicolumn{2}{|c|}{$42.09 \pm 17.32$} & \\
\hline Range & \multicolumn{2}{|c|}{$20.0-62.0$} & \multicolumn{2}{|c|}{$18.0-61.0$} & \\
\hline \multirow{2}{*}{ Past-medical history* } & \multicolumn{2}{|c|}{$\begin{array}{c}\text { Hypothermia } \\
(n=100)\end{array}$} & \multicolumn{2}{|c|}{$\begin{array}{c}\text { Non-hypothermia } \\
(n=130)\end{array}$} & \multirow[t]{2}{*}{ P-value } \\
\hline & No. & $\%$ & No. & $\%$ & \\
\hline DM (hypo glycaemia) & 27 & 27.0 & 13 & 10.0 & $0.001 *$ \\
\hline HTN & 16 & 16.0 & 44 & 33.8 & $0.002 *$ \\
\hline IHD & 2 & 2.0 & 3 & 2.3 & 1.000 \\
\hline COPD & 1 & 1.0 & 3 & 2.3 & 0.635 \\
\hline Hyperthyroidism & 1 & 1.0 & 0 & 0.0 & 0.435 \\
\hline No past medical history & 54 & 54.0 & 75 & 57.7 & 0.576 \\
\hline
\end{tabular}

Ns: There is no significant difference $p$. value $>0.05$

* Statistical significant difference $(p<0.05) \quad$ DM: diabetes mellitus

HTN: hypertension

IHD: ischemic heart disease

COPD: chronic obstructive pulmonary disease

* More than one variables were included.

Table (2): Illustrates BMI of hypothermic and non hypothermic patients.

\begin{tabular}{|c|c|c|c|c|c|}
\hline \multirow[t]{2}{*}{ BMI } & \multicolumn{2}{|c|}{$\begin{array}{c}\text { Hypothermia } \\
(n=100)\end{array}$} & \multicolumn{2}{|c|}{$\begin{array}{c}\text { Non-hypothermia } \\
(\mathrm{n}=130)\end{array}$} & \multirow[t]{2}{*}{ P-value } \\
\hline & No. & $\%$ & No. & $\%$ & \\
\hline Underweight $\quad(<18.5)$ & 32 & 32.0 & 29 & 22.3 & \multirow{4}{*}{$0.000 *$} \\
\hline Normal $\quad(18.5-24.9)$ & 24 & 24.0 & 0 & 0.0 & \\
\hline Overweight $(25-29.9)$ & 28 & 28.0 & 45 & 34.6 & \\
\hline Obese $\quad(30$ or above $)$ & 16 & 16.0 & 56 & 43.1 & \\
\hline Mean \pm SD & \multicolumn{2}{|c|}{$24.27 \pm 5.44$} & \multicolumn{2}{|c|}{$29.18 \pm 5.25$} & $0.000^{*}$ \\
\hline
\end{tabular}

Ns: There is no significant difference $p$. value >0.05

* Significant difference p. value $<0.05 \quad$ BMI: body mass index

Table (3): Mean distribution of hypothermic \&non hypothermic patients according to serum electrolytes.

\begin{tabular}{|c|l|c|c|c|}
\hline \multirow{2}{*}{ Day } & \multirow{2}{*}{ Electrolytes } & $\begin{array}{c}\text { Hypothermia } \\
(\mathbf{n}=\mathbf{1 0 0})\end{array}$ & $\begin{array}{c}\text { Non-hypothermia } \\
(\mathbf{n = 1 3 0})\end{array}$ & \multirow{2}{*}{ P-value } \\
\cline { 3 - 5 } & $\mathbf{M a}$ & Mean \pm SD & Mean \pm SD & \\
\hline \multirow{3}{*}{$\mathbf{1}^{\text {st }}$ day } & $\mathbf{M g}$ & $137.73 \pm 6.34$ & $139.08 \pm 5.51$ & 0.366 \\
\cline { 2 - 5 } & $\mathbf{K}$ & $2.47 \pm 0.25$ & $1.84 \pm 0.41$ & $0.024^{*}$ \\
\hline \multirow{3}{*}{$3^{\text {rd }}$ day } & $\mathbf{N a}$ & $3.86 \pm 0.52$ & $3.36 \pm 0.67$ & $0.016^{*}$ \\
\cline { 2 - 5 } & $\mathbf{M g}$ & $148.50 \pm 2.12$ & $138.36 \pm 5.54$ & $0.029^{*}$ \\
\cline { 2 - 5 } & $\mathbf{K}$ & $2.30 \pm 0.28$ & $2.04 \pm 0.45$ & 0.380 \\
\hline
\end{tabular}


Table (4): Mean distribution of hypothermic and non hypothermic patients according to coagulation profile test.

\begin{tabular}{|c|l|c|c|c|}
\hline \multirow{3}{*}{ Day } & \multirow{2}{*}{ Coagulation profile } & $\begin{array}{c}\text { Hypothermia } \\
(\mathbf{n = 1 0 0})\end{array}$ & $\begin{array}{c}\text { Non-hypothermia } \\
(\mathbf{n = 1 3 0})\end{array}$ & \multirow{2}{*}{ P-value } \\
\cline { 3 - 5 } & & Mean \pm SD & Mean \pm SD & \\
\hline \multirow{3}{*}{$\mathbf{1}^{\text {st }} \mathbf{d a y}$} & PC & $87.50 \pm 17.68$ & $85.89 \pm 16.96$ & 0.884 \\
\cline { 2 - 5 } & PT & $12.85 \pm 0.78$ & $12.90 \pm 1.72$ & 0.464 \\
\cline { 2 - 5 } & INR & $1.04 \pm 0.05$ & $1.13 \pm 0.18$ & 0.129 \\
\hline \multirow{3}{*}{$3^{\text {rd }}$ day } & PC & $85.00 \pm 7.07$ & $86.50 \pm 12.65$ & 0.893 \\
\cline { 2 - 5 } & PT & $12.75 \pm 0.35$ & $13.02 \pm 1.20$ & 0.899 \\
\cline { 2 - 5 } & INR & $1.15 \pm 0.07$ & $1.15 \pm 0.25$ & 0.418 \\
\hline
\end{tabular}

Ns : There is no significant difference p. value >0.05 $P T:$ prothrombin time $P C$ : prothrombin concentration

Table (5): Comparison between the hypothermic \&non hypothermic patients in relation to GCS

\begin{tabular}{|l|c|c|c|}
\hline \multicolumn{1}{|c|}{ GCS } & $\begin{array}{c}\text { Hypothermia } \\
(\mathbf{n = 1 0 0 )}\end{array}$ & $\begin{array}{c}\text { Non-hypothermia } \\
(\mathbf{n = 1 3 0 )}\end{array}$ & P-value \\
\hline Mean \pm SD & $12.08 \pm 4.14$ & $14.88 \pm 1.20$ & $0.000 *$ \\
\hline Range & $3.0-15.0$ & $3.0-15.0$ & 0.0 \\
\hline
\end{tabular}

Ns: *significant difference at p. value $<0.05$

GCS: Glasgow coma scale

Table (6): Comparison between the hypothermic \&non hypothermic patients in relation to type of medication

\begin{tabular}{|c|c|c|c|c|c|}
\hline \multirow[t]{2}{*}{ Drugs } & \multicolumn{2}{|c|}{$\begin{array}{l}\text { Hypothermia } \\
(n=100)\end{array}$} & \multicolumn{2}{|c|}{$\begin{array}{c}\text { Non-hypothermia } \\
(n=130)\end{array}$} & \multirow[t]{2}{*}{ P-value } \\
\hline & No. & $\%$ & No. & $\%$ & \\
\hline Anti-biotic & 100 & 100.0 & 128 & 98.5 & 0.506 \\
\hline Analgesic & 82 & 82.0 & 15 & 11.5 & $0.000 *$ \\
\hline Anti-inflammatory & 41 & 41.0 & 0 & 0.0 & $0.000 *$ \\
\hline Anti-hemorrhagic & 52 & 52.0 & 3 & 2.3 & $0.000 *$ \\
\hline Anti-coagulant & 3 & 3.0 & 97 & 74.6 & $0.000 *$ \\
\hline Anti-emetic & 89 & 89.0 & 70 & 53.8 & $0.000 *$ \\
\hline Bronchodilator & 1 & 1.0 & 18 & 13.8 & $0.000 *$ \\
\hline Anti-pyretic & 0 & 0.0 & 57 & 43.8 & $0.000 *$ \\
\hline Anti-epileptic & 0 & 0.0 & 29 & 22.3 & $0.000 *$ \\
\hline Anti-diabetic & 24 & 24.0 & 15 & 11.5 & $0.013 *$ \\
\hline Anti-hypertensive & 15 & 15.0 & 47 & 36.2 & $0.000 *$ \\
\hline Diuretic & 2 & 2.0 & 20 & 15.4 & $0.001 *$ \\
\hline Anti-arrhythmic & 1 & 1.0 & 6 & 4.6 & 0.142 \\
\hline Memory & 1 & 1.0 & 21 & 16.2 & $0.000 *$ \\
\hline Electrolytes & 97 & 97.0 & 3 & 2.3 & $0.000 *$ \\
\hline Vitamins & 2 & 2.0 & 39 & 30.0 & $0.000 *$ \\
\hline
\end{tabular}

Ns: There is no significant difference $p$ value $>0.05 \quad$ *Significant difference $p$ value $<0.05$

Table (7): Distribution of hypothermic patients according to hypothermia assessment.

\begin{tabular}{|l|c|c|}
\hline \multicolumn{1}{|c|}{ Items } & No.(n= 100) & \% \\
\hline Time of developing hypothermia: (days) & & \\
\hline <3 days & 99 & 99.0 \\
\hline 3-7 days & 0 & 0.0 \\
\hline$>7$ days & 1 & 1.0 \\
\hline Degree of hypothermia: & 99 & 99.0 \\
\hline Mild ( core body temperature 32 c to 35 c ) & 1 & 1.0 \\
\hline Moderate (core body temperature 28c to 32c) & 0 & 0.0 \\
\hline Severe ( core body temperature < 28c ) & & 99.0 \\
\hline
\end{tabular}




\begin{tabular}{|l|c|c|}
\hline \multicolumn{1}{|c|}{ Items } & No.(n= 100) & \% \\
\hline Stage of hypothermia: & & \\
\hline Stage I (conscious, shivering ) & 99 & 99.0 \\
\hline Stage II (Impaired consciousness, not shivering ) & 1 & 1.0 \\
\hline Stage III (Un conscious, not shivering,vital signs present) & 0 & 0.0 \\
\hline Stage IV (No vital signs ) & 0 & 0.0 \\
\hline Duration of hypothermia: (hours) & & \\
\hline$<2$ & 19 & 19.0 \\
\hline $2-3$ & 44 & 44.0 \\
\hline $3-8$ & 37 & 37.0 \\
\hline Body part which hypothermia started & & \\
\hline Feet & 13 & 13.0 \\
\hline Hands & 82 & 82.0 \\
\hline Nose & 0 & 0.0 \\
\hline Ears & 5 & 5.0 \\
\hline
\end{tabular}

Table (8): Distribution of hypothermic patients according to rewarming manoeuver $(n=100)$.

\begin{tabular}{|l|c|c|c|c|c|c|}
\hline \multirow{2}{*}{ Rewarming device used* } & \multicolumn{2}{|c|}{ Total (n= 100) } & \multicolumn{2}{c|}{ Effective } & \multicolumn{2}{c|}{ Not effective } \\
\cline { 2 - 8 } & No. & \% & No. & \% & No. & \% \\
\hline Warming environment and clothing & 5 & 5.0 & 1 & 20.0 & 4 & 80.0 \\
\hline $\begin{array}{l}\text { Warming intravenous fluidsandblood } \\
\text { products }\end{array}$ & 33 & 33.0 & 25 & 75.8 & 8 & 24.2 \\
\hline Warming blankets & 99 & 99.0 & 76 & 76.8 & 23 & 23.2 \\
\hline Ensure dry & 13 & 13.0 & 3 & 23.1 & 10 & 76.9 \\
\hline Cover-close wound & 97 & 97.0 & 11 & 11.3 & 86 & 88.7 \\
\hline
\end{tabular}

* More than one variables were included.

Table (9): Distribution of hypothermic patients according to patients outcome $(\mathrm{n}=100)$.

\begin{tabular}{|l|c|c|}
\hline \multicolumn{1}{|c|}{ Items } & No. $(\mathbf{n = 1 0 0})$ & \% \\
\hline Complications*: & & 40.0 \\
\hline Hypotension & 40 & 99.0 \\
\hline Shivering & 99 & 6.0 \\
\hline Hypovolemia and hypomagnesaemia & 6 & 8.0 \\
\hline Metabolic acidosis. & 8 & 1.0 \\
\hline Hypokalemia. & 1 & 30.0 \\
\hline Hypoglycaemia & 30 & 3.0 \\
\hline Bradycardia and other cardiac arrhythmia & 3 & 1.0 \\
\hline Death & 1 & \\
\hline Patient survival: & & 99.0 \\
\hline Survive & 99 & 1.0 \\
\hline Dead & 1 & \\
\hline ICU stay: (days) & & 94.0 \\
\hline One day & 94 & 6.0 \\
\hline More than one day & 6 & \\
\hline
\end{tabular}

* More than one variables were included. 
Table (1): Represents Personal characteristics and clinical data of the hypothermic and non hypothermic patients. It was noticed that $66 \%$ of the hypothermic groups were male versus $56.9 \%$ of the non hypothermic groups . Regarding to age, it was found that the mean age of hypothermic patients was $37.65 \pm 11.80$ years versus $42.09 \pm 17.32$ years in non hypothermic groups with .No statistical significant difference was found regards sex and age between hypothermic and non hypothermic patients .Regarding past medical history, it was noticed that $54 \%$ and $57.7 \%$ respectively of hypothermic and non hypothermic patients had no past medical history . There were statistical significant differences between both groups regarding DM and HTN ( $=0.001 \& 0.002)$ respectively .

Table (2): Illustrates body mass index (BMI) of hypothermic and non hypothermic patients . It was found that the mean \pm SD BMI of hypothermic patients was $24.27 \pm 5.44$ versus $29.18 \pm 5.25$ of non hypothermic groups with statistical significant difference $(p=0.0001)$. This indicates that $32 \%$ of hypothermic patients were underweight and $43.1 \%$ of non hypothermic patients were obese .

Table (3): Shows serum electrolytes between hypothermic and non hypothermic patients. This table represents that there was statistical significant difference between hypothermic and non hypothermic patients in relation to $\mathrm{Mg}$ and $\mathrm{K}$ at first day of ICU stay ( $p=0.024 \& 0.016)$ respectively . At third day of ICU stay , it was noticed that there was statistical significant difference between hypothermic and non hypothermic patients related to $\mathrm{Na}(\mathrm{p}=0.029)$.

Table (4): Shows coagulation profile test between hypothermic and non hypothermic patients. At first day and third day, It was noticed that there was no statistical significant difference was put into evidence between the hypothermic and non hypothermic patients in relation to coagulation profile .

Table (5) : shows that the mean \pm SD of hypothermic and non hypothermic patients was $(12.08 \pm 4.14)$ $(14.88 \pm 1.20)$ respectively with statistical significant difference $(\mathrm{p}=0.0001)$.

Table (6): represents comparison between the hypothermic \&non hypothermic patients as regard to type of medications. It was noticed that all hypothermic patients administered antibiotic versus $98.5 \%$ of non hypothermic patients. Statistical significant difference were found between two groups in relation to all type of medications except antibiotic .

Table (7): Shows assessment of hypothermia . It was noticed that majority $(99 \%$ )of hypothermic patients developed hypothermia in less than three days. Regarding to degree of hypothermia , majority (99\%) of hypothermic patients had mild degree of hypothermia . As regard stage of hypothermia, it was noticed that majority (99\%) of hypothermic patients had stage one of hypothermia . As regard to duration of hypothermia, it was noticed that $44 \%$ of hypothermic patients were lasted with hypothermia for two to three hours. As regard to body part which hypothermia started, it was noticed that $82 \%$ of hypothermic patients were started with hypothermia in hands .

Table (8): Shows the distribution of hypothermic patients according to the rewarming manoeuver. It was noticed that (99\%)of hypothermic patients were used rewarming blanket and this was effective in $(76.8 \%)$ of patients .

Table (9): Showsthe distribution of hypothermic patients according to patients out come. It was noticed that majority (99\%) of hypothermic patients had shivering and survived, respectively. Regarding to ICU stay, it was noticed that $94 \%$ of hypothermic patients were stayed in ICU for one day.

\section{Discussio:}

The current study was clarified that more than half of hypothermic patients were male. The result of current study agrees with (Mallet, 2002) who reported that the frequency of hypothermia among men might be 2.5 to 4 times greater than for women .This is due to high levels of exposure to environmental risk factors among men. More over, the present study agreed with (Balvers et al., 2016) who reported that the majority of hypothermic patients were males .On the other hand, This finding was inconsistent with (Seman et al., 2010) who mentioned that men and women are equal at risk for hypothermia .

The result of the present study revealed that the age of hypothermic patient ranged from $20-62$ year. In the same line with (Balvers. et al., 2016) who reported that the average range of hypothermic and non hypothermic patients were more than 20 to less than 65 respectively with no statistical significant difference .

From the findings of the current study, it appeared that half of hypothermic patients had no past medical history .This comes in inferior of study done by (Seman et al., 2010) who reported that the hypothermic patients had frequent associations of diseases the most frequent being systemic hypertension and DM. And also the study finding was inconsistent with (Kosinski et al., 2015) who said that the majority of hypothermic patients were developed hypothermia alongside with other chronic disease. 
As regard body mass index the present study found that underweight was marked among hypothermic patients. On the other hand, the obesity was noticeable among non hypothermic patients .This finding was nearly similar to the result of (Vazin et al., 2016) who mentioned that a lower rate of body mass index (underweight) increase the risk at critical point in development of hypothermia .

In the current study as regard glasgow coma scale, it was found that the score of GCS in hypothermic patients was less than score in non hypothermic patients so non hypothermic patients are able to create heat by providing properly dry warm clothing or blankets, warming diet, warm sweet drinks and active movement. All these methods of passive external rewarming correct hypothermia. (John, 2010).

As regard type of medication, the current study showed that all hypothermic patient were administered antibiotic. This finding was in consistent with (Seman et al., 2010) who reported that the majority of hypothermic patient administered antihypertensive, antipsychotic and alpha - blockers drugs this class of medications administered to patient may induce hypothermia for patient and make them high risk for hypothermia.

In the current study, it was found that the majority of hypothermic patients had mild degree of hypothermia. This due to hypothermia was early noticed in the studied patients because measurement of body temperature is routinely procedure done at ICU . When hypothermia detected patient was not delayed to take treatment and rewarming with appropriate manoeuver. This is similar to the study done by (Kosinski et al., 2015) who reported that mild hypothermia was diagnosed in the majority of patients .

In the current study, it was observed that the majority of hypothermic patients had stage I of hypothermia (conscious, shivering). This due to majority of studied patients were adult, healthy, oriented, had less chronic disease and not delayed to rewarming them with appropriate manoeuver. Similar to this observation, study done by (Kosinski et al., 2015) who reported that majority of hypothermic patients had stage I of hypothermia .

As regard to body part which hypothermia started, it was observed that the majority of hypothermic patients started with hypothermia in hands. This due to some body parts were more susceptible to hypothermia, hands one of them . these extremities (hands ) usually cool faster than other body part and if patient suffers from poor circulation in these extremities and these extremities had the least protection from the cold environment become more liable to hypothermia. (Davis, 2016)
As regard to rewarming manoeuver, the current study was clarified that the majority of hypothermic patients were rewarmed by rewarming blanket. This is due to the accessibility of rewarming blanket in ICU as routinely manoeuver in rewarming hypothermic patients . This disagree with (Kosinski et al., 2015 ) who reported that the majority of hypothermic patients were warmed by intravenous fluid and two third of patients were warmed by means of forced air warming or carbon - fiber blanket. The present study revealed that rewarming blanket was most effective rewarming manoeuver with hypothermic patients. The study finding was inconsistent with (Danzel et al., 2016) who reported that no significant difference was found between the different method of rewarming but there was a tendency choosing active internal rewarming by gastric or colonic lavage and another style against active external rewarming with hot baths or electric blankets .

In the current study the shivering was the most complication among the hypothermic patients. This due to hypothalamus stimulates skeletal muscles to shiver to produce heat (Perlman. et al., 2016) In mild hypothermia, the body first senses cold stress via the afferent fibers of cold receptors and peripheral vasoconstriction occurs. Shivering increases metabolic demand, which elevates the heart rate and increases cardiac output, respiratory rate and overall oxygen consumption (Rischall et al., 2016) In the absence of shivering (when paralyzed with neuromuscular blocking agent) the metabolic rate will decrease by $8 \%$ for each degree of heat lost. (Perlman. et al., 2016).

Regarding to patient outcome, the present study showed that majority of hypothermic patients were survived .This due to half hypothermic patients in the current study had no past medical history of chronic disease and establish early treatment for hypothermia . This result disagree with (Vassal et al., 2008) who reported that mortality among hypothermic patients is highly and depend on age, background of chronic disease, the delay before treatment and rewarming modality used .

More over, (Seman et al., 2010 ) who reported that the mortality rate for hypothermic patients were more than half with half of them death occur during hypothermia and the other half after reversal through rewarming this due to rewarming shock and after drop. 


\section{Conclusion(s)}

In the light of the study results, the following conclusions can be drawn

- There was statistical significant difference between hypothermic and non hypothermic patients related to DM (hypoglycaemia), underweight and low GCS.

- Different rewarming methods were used to treat hypothermic patients which reflect the effectiveness of these methods in treatment patients and prevention of complication. The blanket was most effective rewarming manoeuver used in treat hypothermic patients .

\section{Recommendations}

- In the light of the results of this study the following recommendations will be suggested:

- Emphasize the importance of accurate monitoring of body temperature to provide early detection of hypothermia and toprotect patient against further heat loss and monitor cardiac rhythm .

- Studying physiological effects hypothermia on different parts of body to identify importance of detection of hypothermia in early phase.

- Studying different rewarming methods which used to treat hypothermic patient .

- Provide early application of rewarming manoeuver to reduce heat loss and warm the hypothermic patients in order to achieve and maintain normothermia .

- Fluid therapy with warmed IV fluids concurrent with external rewarming is recommended to avoid rewarming shock and after drop.

- Provide adequate monitoring when using heading pads to rewarm a hypothermic patient because burns may result due to decreased sensation and reduce blood flow body surface .

- Reapply this research on a larger probability sample acquired from different geographical area in Egypt for generalization.

\section{References}

1. Adam S., \& obsorne S., (2012): critical care nursing science and practice, chapter11, P.P( 337), oxford university press.

2. Balvers K., Vander M., Graumans M., Boer C., Binnekade J., Goslings J., Juffermans N., (2016): Hypothermia as a predictor for mortality in trauma patients at admittance to the intensive care unit. J Emerg Trauma Shock, Vol.9, NO. 3, P.P(97 -102), Available at: http://www. onlinejets.org .

3. Danzel D., Hedges J., \& Pozos R., (2016): Hypothermia outcome score development and implications, Critical care med, Vol 15, P.p (310).
4. Davis. C., (2016): Hypothermia (extended exposure to cold) Health and living center, prevention and wellness, Available at: http://www.medicine net.com .

5. John. M., (2010): Hypothermia, rosen's emergency medicine, concept and clinical practice, 7th, Wikipedia.

6. James. L., (2016): hypothermia, drugs and diseases emergency medicine, Symptoms checker ,Available at http:// e medicine. medscape .Com.

7. Laupland K., Zahar J., Adire C., Minet C., Vesin A., Goldgran -Toledano D., Azoulay E., Garrouste - Orgeas M., Cohen Y., Schwebel C., Jamali. S., Darmon M., Dumenil A., Kallel H., Souweine B., \& Timsit J., (2012): Severe hypothermia increases the risk for intensive care unit-Acquired infection, oxford university press, Clinical infectious diseases , Available at : http:// cid . oxford journals .org .

8. Kosinski S., Darocha T., Galazkowski R., \& Drwila R., (2015) : Accidental hypothermia in poland - estimation of prevalence, diagnostic methods and treatment, Scandinavian Journal of trauma, Resuscitation and Emergency Medicine ,Vol.23 ,NO. 13 ,P.P (2-6) .

9. Mallet M., (2002): Pathophysiology of accidental hypothermia, QJM, Rev Assoc med Bras ,Vol 35 ,No 7, P.p(15-20) .

10. Mcculough L., \& Arora S., (2004): Diagnosis and treatment of hypothermia, American family physician, Vol 70, NO. 12, Available at : http: //www.aafp.org/off.

11. Peiris A., (2018): Hypothermia, American medical association national institute on aging, JAma patient page,Weather-safety, Vol;319, No(12), doi:10.1001/jama. 2018, Available at :http://www Jamanetwork. com/ Journals/ JAMA.

12. Perlman, R., Callum J., laflamme C., Tien H., Nascimento B., Beckett A., \& Alam A., (2016): Arecommended early goal-. Directed management guideline for the prevention of hypothermia- Related transfusion Morbidity and mortality in severely injured trauma patients, critical care, vol20, Biomed central, Available at:http://creative commons.org.

13. Rischall M., Rowland F., Cantrill S., \& Havryliuk T., (2016): Evidence- Based management of accidental hypothermia in the emergency department, emergency medicine practice, voL18, Available at : www.eb medicine .net .

14. Seman A., Golim V., \& Gorzoni M., (2010): A study of accidental hypothermia in 
institutionalized elderly, ACCP critical care board review, Vol .15 ,NO .35 , P.P (321 -331 ), Available at: www.Rev Assoc med Bras .net.

15. Thompson H., Kirkness C., \& Mitchell P., (2013): Hypothermia and rapid rewarming is associated with worse outcome following traumatic brain injury, $\mathrm{J}$ trauma nurse, National center for biotechnology information, National library of medicine .

16. Vassal T., \& Guidet B., (2008): Severe accidental hypothermia treated in an ICU, Clinical investigation in critical care, Vol.120, NO. 6, P.P (1998-2002), Available at : http://www.chest journal.org .

17. Vazin M., Larsen V., \& Jensen K., (2016): Survival from severe accidental hypothermia in an elderly woman, Journal of Anesthesia clinical research, Vol .7 ,NO.6. 